\title{
Saúde Mental e o Campo Sociojurídico: o "estado da arte do debate" com a Reforma Psiquiátrica'
}

\section{Mental Health and the Social-judicial Field: the "state of the art of debate" with the Psychiatric Reform}

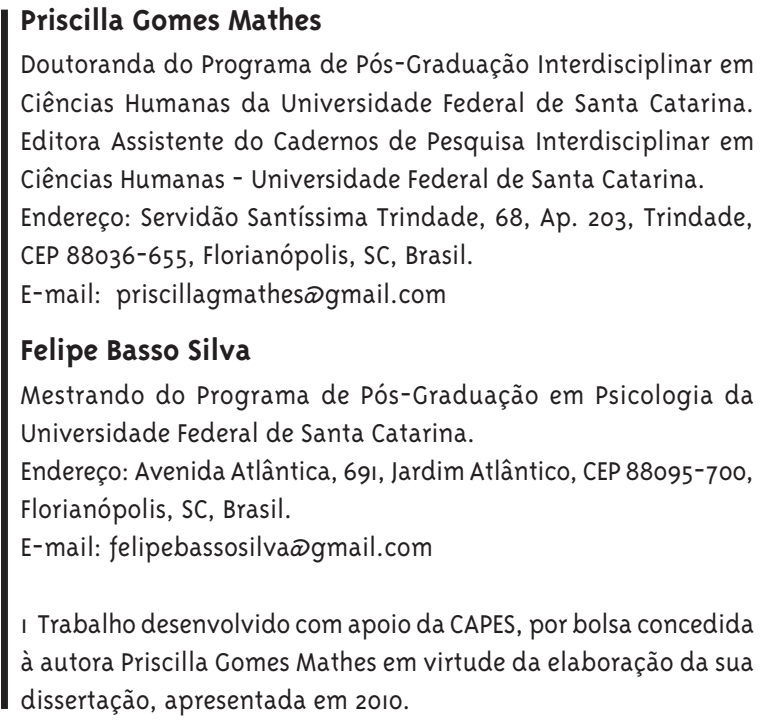
CEP 88036-655, Florianópolis, SC, Brasil.

E-mail: priscillagmathesळgmail.com

Felipe Basso Silva

Mestrando do Programa de Pós-Graduação em Psicologia da Universidade Federal de Santa Catarina.

Endereço: Avenida Atlântica, 691, Jardim Atlântico, CEP 88095-700, Florianópolis, SC, Brasil.

E-mail: felipebassosilvaœgmail.com

I Trabalho desenvolvido com apoio da CAPES, por bolsa concedida à autora Priscilla Gomes Mathes em virtude da elaboração da sua dissertação, apresentada em 2010.

\section{Resumo}

No presente trabalho, pretende-se traçar uma trajetória do tema da saúde mental no campo sociojudiciário, com o objetivo de tentar visualizar o "estado da arte do debate" da produção acadêmica dessa temática na última década (2001-2011) nas áreas de produção de conhecimento das ciências humanas e sociais aplicadas (CAPES, 2009). Essa problemática aparece como uma questão relevante para ser objeto de pesquisa em decorrência de mudanças ocorridas em diversos espaços da saúde mental a partir do movimento de reforma psiquiátrica ocorrido no Brasil. Este trabalho apresenta um caráter inovador, considerando o ineditismo da construção do "estado da arte" sobre a temática da saúde mental, sendo assim, de caráter eminentemente exploratório. Visando alcançar os objetivos propostos, realizou-se a construção de uma base de dados como instrumento para observar o universo de trabalhos encontrados em torno da temática da saúde mental no campo sociojudiciário, nos principais meios de publicação com acesso virtual. Identificou-se, contudo, que, apesar dos avanços percebidos nas políticas públicas da área da saúde mental neste país, a produção científico-técnica não parece ter acompanhado essas modificações com a mesma intensidade.

Palavras-chave: Saúde Mental; Reforma Psiquiátrica; Produção de Conhecimento. 


\section{Abstract}

In the present paper we aim to outline the trajectory of the theme of mental health in the social-judicial field, in an attempt to visualize the "state of the art of debate" of the academic production on this theme in the last decade (2001-2011), in the knowledge production areas of the applied human and social sciences (CAPES, 2009). This problem emerges as a relevant issue to be object of research due to changes that have occurred in several mental health spaces after the psychiatric reform movement that took place in Brazil. This paper has an innovative character, in view of the originality of the construction of the "state of the art" on the issue of mental health. Therefore, it has an eminently exploratory character. In order to achieve the proposed objectives, a database was constructed as a tool for analyzing the universe of works that were found about the theme of mental health in the social-judicial field in the main means of publication with virtual access. However, it was identified that, despite the advances perceived in the public policies in the area of mental health in this country, the scientific-technical production does not seem to have accompanied these changes with the same intensity.

Keywords: Mental Health; Psychiatric Reform; Knowledge Production; "State of the Art of Debate".

\section{Introdução}

A partir de pesquisas anteriores na área do serviço social, observou-se que alguns campos temáticos têm sido negligenciados, sendo marcados por uma fraca presença de pesquisas. (Mitjavila, 2006; Mathes, 2007). Como exemplo, verifica-se a parca presença de textos referentes ao campo sociojudiciário no conjunto da produção científica publicada nos meios de divulgação relevantes da área. Apesar das temáticas de cunho macro-social constituírem a coluna vertebral de uma tradição intelectual bem estabelecida nos âmbitos acadêmicos do serviço social, essa característica não se verifica neste segmento da produção.

Dessa forma, pretende-se com esta pesquisa traçar uma trajetória do tema da saúde mental no campo sociojudiciário, com o objetivo de tentar visualizar o "estado da arte do debate" da produção acadêmica dessa temática na última década (20012011) nas áreas de produção de conhecimento das ciências humanas e sociais aplicadas (CAPES, 2009), em decorrência de mudanças ocorridas em diversos espaços da saúde mental a partir do movimento de reforma psiquiátrica. (Mathes, 2010). Reconhecese aqui essa intersecção entre a saúde mental e o campo sociojurídico como um espaço privilegiado para análises sociais da realidade atual, pois o campo sociojudiciário, da mesma forma que outros (médico-sanitário, educativo etc.), representa uma questão relevante no tecido social, devido a sua notória participação nos processos de regulação das relações indivíduo-sociedade.

Destaca-se aqui o caráter inovador da presente proposta, considerando o ineditismo da construção do "estado da arte" sobre a temática da saúde mental no campo sociojudiciário nas áreas de produção de conhecimento das ciências humanas e sociais aplicadas, sendo assim, de caráter eminentemente exploratório. Este trabalho, então, não pretende compreender a totalidade dos materiais já publicados nem esgota a análise da literatura levantada, mas é um esforço inicial neste sentido. 


\section{- Campo Sociojudiciário e a Saúde Mental}

A área criminal pode ser caracterizada por historicamente ter um caráter matricial na incorporação de conhecimento científico-técnico aos processos modernos de administração de justiça e também na construção dos próprios domínios disciplinares de alguns campos de conhecimento e de intervenção profissional, vinculados ao julgamento de crimes e administração de penas, como seria o caso da psiquiatria forense (Darmon, 1991; Rebelo, 2004). Dessa forma, ela se mostra como uma área relevante para analisar esse espaço de intersecção entre o jurídico e o social.

O campo sociojurídico é definido por Mitjavila em termos de seu papel de articulação entre o social e jurídico, na medida que o direito é concebido como meio para a satisfação de necessidades acompanhando, neste sentido, a formulação de políticas. Portanto, justiça e políticas não constituem campos de análise separados. Sua institucionalidade materializa-se em mecanismos de regulação social, a partir dos pressupostos que sustentam a funcionalidade do controle social nas sociedades modernas, em função dos quais deve existir algum tipo de correspondência entre normas jurídicas e normas sociais (p. 82, 2006).

Ademais, o campo sociojudiciário tem nesse espaço um conjunto relevante de competências de natureza simbólica, pois promove a socialização de expectativas referentes à legitimidade das normas legais e também à produção e reprodução dos universos simbólicos que são dominantes em cada contexto sócio-histórico nos quais se desenvolve.

Desde a segunda metade do século XIX, a psiquiatria forense tem historicamente ocupado esse espaço de intersecção entre a medicina, a justiça e o social, como tem sido contundentemente mostrado pelo acervo de investigação sócio-histórica atualmente disponível (Harris, 1993). O próprio surgimento da criminologia está fortemente dominado pela medicina como área de conhecimento e como profissão. As ideias médicas sobre a loucura e a periculosidade, sobre o normal e o patológico converteram-se em elementos decisivos na trajetória da medicina como profissão, especialmente no que se refere à ampliação indefinida de seus objetos de intervenção, cada vez mais sociais e biopolíticos (Mitjavila, 20o6; Foucault, 1978).

As práticas profissionais (discursivas e não discursivas) da psiquiatria forense encontram-se estreitamente relacionadas com a construção dos modelos etiológicos e terapêuticos e a divisão sociotécnica do trabalho sobre as relações entre doença mental e criminalidade. Estudos disponíveis sobre origens e trajetórias da psiquiatria forense no espaço político-institucional simultaneamente associados à loucura e à criminalidade demonstram a significativa presença dos quadros de referência teóricos e ideológicos oriundos de movimentos como o higienismo. Efetivamente, a participação do saber médico no âmbito do campo sociojurídico não pode ser analisada à margem dos processos mais amplos por meio dos quais são organizadas as respostas sociopolíticas ao crime e à loucura, a partir de finais do século XIX e até o presente (Mitjavila, 2004; Mitjavila e Ortega, 2005).

A partir dessa construção histórica, o campo da saúde mental como tema de estudos tem garantido aos outros saberes participantes desse espaço uma inscrição fortemente subordinada à psiquiatria e aos saberes "psi" responsáveis pela formulação das bases epistemológicas e as configurações de podersaber que organizam a gestão social das relações entre doença mental e criminalidade. Com isto, a análise da presença dos saberes advindos do campo social nesse espaço não pode negligenciar as condições que decorrem dos processos históricos pelos quais o saber médico instalou-se como o mais legítimo dos saberes nesse campo e obteve monopólio, mandatos institucionais e licença quase sem limites para medicalizar alguns processos vinculados à gestão da criminalidade nas sociedades ocidentais (Mitjavila, 2006; Freidson, 1988).

Contudo, segundo Adorno (1991), as políticas públicas penais brasileiras mostram-se com uma orientação bastante eclética quanto aos pressupostos etiológicos da criminalidade e suas relações com a doença mental. Isto também se reflete no estatuto ambíguo do doente mental no Brasil, pois "[...] a sua doença é o móvel de seu ato, excluído por isso a culpabilidade e a responsabilidade. $\mathrm{Na}$ 'estratégia 
da periculosidade', a punição justifica-se como tratamento, e a prevenção fundamenta-se em um ato passado" (Peres e Nery Filho, p. 19, 2002).

\section{Reformas na Legislação Brasileira: visibilizando o movimento de Reforma Psiquiátrica}

De acordo com os estudos disponíveis (Venâncio, 2003), durante as três primeiras décadas do século XX, o movimento da higiene mental ganha um forte impulso no Brasil, a partir da articulação de elementos do alienismo francês, do cientificismo organicista da psiquiatria alemã, e dos projetos políticos voltados para o enfrentamento dos problemas sociais. Nesse período, ocorre no Brasil a transformação do asilo em hospital psiquiátrico. Trata-se de uma transformação que instituirá o mandato social para a psiquiatria cumprir um papel específico na organização das respostas sociais, e particularmente estatais, ao problema social gerado pela loucura. No entanto, a instituição asilar, mesmo quando começou a adotar uma estrutura hospitalar, não teve um surgimento e distribuição homogêneos no Brasil. No período da Primeira República, apenas alguns estados da União criaram asilos ou colônias de alienados, o que terá repercussões no desenvolvimento da assistência e formação dos psiquiatras ao longo do século XX (Machado e col., 1978; Jabert, 2005).

Na primeira legislação criminal brasileira, que corresponde ao Código Criminal do Império do Brasil (1830), não foi previsto nenhum tipo de tratamento especial para os "loucos de todo gênero" que houvessem cometido crimes. Devido a isso, eles geralmente eram confinados nas instituições a eles reservadas ou no seio dos próprios lares, cabendo a decisão exclusivamente ao juiz. A obrigatoriedade de realização de perícias médicas e a criação de asilos e ou de alas especiais para os doentes mentais criminosos vai concretizar-se recém em 1903, a partir do Decreto 1.132, impulsionado pela atuação legislativa de Teixeira Brandão. Nesse momento, foi aprovado o Regulamento de Assistência a Alienados do Distrito Federal. Somente então foram previstas legalmente tanto a obrigatoriedade da realização de perícia médica para internação em manicômios quanto a necessidade da criação de alas especiais para os loucos criminosos nos asilos para alienados existentes (Carrara, p. 49, 1987).

A malha institucional brasileira nesta área se mantém, até o presente, bastante heterogênea e complexa. De fato, a maioria dos Estados brasileiros não dispõem de unidades de tratamento psiquiátricoforense, além de serem inúmeras as cidades brasileiras que não possuem peritos oficiais em psiquiatria forense (Abdalla-Filho e Engelhardt, 2003).

É a lei, por meio do Código Penal Brasileiro - Lei no 2.848, de 7 de dezembro de 1940 - que apresenta uma primeira concepção do indivíduo inimputável. Segundo o artigo 26, é "isento de pena o agente que, por doença mental ou desenvolvimento mental incompleto ou retardado, era, ao tempo da ação ou da omissão, inteiramente incapaz de entender o caráter ilícito do fato ou de determinar-se de acordo com esse entendimento". Esse é o indivíduo criminoso destituído de razão (Pavezi, 2009).

Ou seja, efetivamente, a partir do Código de 1940, a doença mental passa a ser considerada causa excludente de culpabilidade. Isto porque este código apresenta dois tipos de resposta social: a pena, sendo definida de acordo com o grau de culpabilidade do indivíduo e a gravidade de seu ato; e a medida de segurança, baseada na avaliação do nível de periculosidade do acusado. Com isto, passava a ser competência dos psiquiatras a avaliação do "estado perigoso" daqueles que tivessem cometido algum crime. Esta medida de segurança, ao mesmo tempo que alcança os "loucos criminosos", garantelhes sua absolvição do ponto de vista penal. Ou seja, esses doentes mentais não podem sofrer alguma punição, mas devem receber tratamento. Para isto há a necessidade da medida de segurança com internação em manicômio judiciário, especialmente pela periculosidade do paciente presumida por lei. Na verdade, a medida de segurança era não somente aplicável aos doentes mentais que infringissem a Lei, mas também a alguns casos específicos como os reincidentes em crimes dolosos e/ou aos aliados de quadrilha de criminosos (C.P. art. 78) (Mitjavila, 2009; Cohen, 1999). Em 1984, o Código Penal de 1940 teve sua Parte Geral revisada, reservando a qualificação de periculosidade social apenas aos doentes mentais que infringirem a Lei (C.P. art.97), 
restringindo a medida de segurança para os doentes mentais penalmente inimputáveis.

Houve também nesse ano a promulgação da Lei de Execução Penal (LEP), n. 7.209, de 11 de julho de 1984, criada com três objetivos principais: garantir o bem-estar do condenado; classificar o indivíduo e individualizar sua pena; e dar assistência durante o período de cumprimento da pena. Contudo, quanto à sua efetividade, percebe-se "um grande abismo" entre a realidade e a legislação, dando a sensação de "letra morta" à Lei de Execuções Penais.

Aqui cabe ressaltar que Escorel (1905, p. 49, apud Peres e Nery Filho, p. 339, 2002) comenta o Código Penal, destacando a diferença existente entre imputabilidade e responsabilidade. Se imputar relaciona-se com atribuir uma ação a um sujeito, a imputabilidade é uma qualidade que garante uma relação causal entre alguém e uma ação, que aqui é delituosa. Já a responsabilidade está relacionada com as consequências do ato praticado. Assim, os loucos não são responsáveis pelos atos cometidos por estarem compreendidos no parágrafo 4 do artigo 27 como inimputáveis, se não lhes são atribuídos os atos, tampouco respondem legalmente por eles, estando isentos de sanções penais. Se a estratégia alienista já se ocupava com o controle social, a questão dos doentes mentais perigosos aparece como mais uma função.

De acordo com o novo Código Civil, há a possibilidade, segundo seu artigo 1.772, da interdição parcial: "pronunciada a interdição [...] o juiz assinará segundo o estado, o desenvolvimento mental do interdito, os limites da curatela". Isso permite que o juiz limite a curatela, para que o doente mental possa praticar alguns atos da vida civil sem a interdição total. Já àquele que estava interditado totalmente, antes do atual Código Civil, é possível a revisão dessa interdição, visando alcançar uma interdição parcial. Caso o curador não quiser fazer o requerimento, o Ministério Público pode ser acionado. Este código aplica-se também ao usuário de álcool e outras drogas, pois estes estão com a saúde mental comprometida, ou que possuem transtorno mental decorrente do uso de álcool e drogas. Aqui a perícia médica será necessária para uma avaliação acerca do grau de comprometimento mental pelo uso do álcool e/ou outras drogas. Cabe destacar a diferença entre curatela e tutela, pois aquela é específica para os incapazes por problemas mentais, assim como para os ébrios habituais, os viciados em tóxicos e também os pródigos, enquanto que a tutela é somente para o menor de idade sem representante legal (Alves, 2004).

Se no Brasil, reformas na legislação contribuíam com modificações sociais, Basaglia (1924-198o), como diretor do manicômio Gorizia (cidade italiana), já em 1961 realiza mudanças significativas no ambiente, através da criação de uma comunidade terapêutica e da reinserção de vários pacientes internados na sociedade. Para ele, em alguns casos, a loucura, a letargia e falta de ânimo dos pacientes na realidade era consequência do ambiente do hospício. Ou seja, era imprescindível trazer a comunidade para o hospital, garantindo a convivência dos pacientes com outras pessoas. Contudo, não foi ele que elaborou o termo antipsiquiatria, o qual foi criado por David Cooper que, juntamente com Ronald Laing - ambos psiquiatras - firmou em Londres as bases da antipsiquiatria. A ideia principal é a da aproximação do terapeuta com o paciente doente mental, tornando mais humano o tratamento e acelerando o processo de cura. Eles aproximaram-se de teorias sistêmicas, priorizando o tratamento pelo consciente. Mas, as contribuições do pensamento de Franco Basaglia, psiquiatra italiano, responsável por promover uma importante reforma no tratamento dos doentes mentais italianos, foram fonte histórica e política para o movimento de reforma psiquiátrica no Brasil. Ele pretendia realizar uma transformação institucional no campo da psiquiatria, buscando um rompimento com a psiquiatria enquanto ideologia. Sua ideia pode ser dividida em quatro premissas fundamentais, quais sejam, (i) o desmonte da forma tradicional dos manicômios, do aparato manicomial, isto é, lutando contra a institucionalização; (ii) o movimento a favor da incorporação de saberes científicos capazes de gerar novas ideologias e novas intervenções manicomiais; (iii) a substituição da tutela por um "contrato social"; e (iv) realização dessas transformações através de mudanças no campo político e social (Amarante, 1994).

Ainda que a antipsiquiatria tenha mexido com os profissionais dos manicômios, sua proposta não conseguiu se concretizar na prática. Basaglia, po- 
rém, tinha o horizonte político como um diferencial. Ele pretendia mudar não apenas o atendimento, mas especialmente as leis de assistência ao doente mental, visando, por exemplo, a aposentadoria financiada pelo Estado para o doente mental. Cabe destacar ainda a influência no Brasil do movimento, desenvolvido no contexto norte-americano e liderado pela Organização Pan-americana de Saúde, da psiquiatria comunitária.

No contexto de crise nacional dos anos de 1980 - crise do petróleo, aumento da dívida externa, crise política e social decorrente do regime ditatorial, crise de gestão previdenciária - iniciam-se, no Brasil, movimentos em busca de uma "reforma sanitária", sinalizando a estruturação do movimento de Reforma Psiquiátrica nacional. Com isso emerge no Brasil o debate acerca do papel do hospital psiquiátrico. A I Conferência Nacional de Saúde Mental tem destaque nesse processo, pois busca tratar de temas acerca dos direitos civis dos internados, condições de manutenção da dignidade humana e a superação das tendências de internações hospitalares (Gastal, 2007).

Nesse período, um marco histórico para o movimento de reforma psiquiátrica foi a Conferência Regional para a Reestruturação da Assistência Psiquiátrica que gerou o documento hoje intitulado de "Declaração de Caracas". Neles os países presentes, inclusive o Brasil, comprometem-se em assegurar os direitos civis e a dignidade humana dos internados, bem como promover a reestruturação da assistência psiquiátrica, assegurando a diminuição do papel hegemônico do hospital psiquiátrico. No início do século XXI, os países que compuseram a Conferência Regional para a Reestruturação da Assistência Psiquiátrica revisaram os avanços obtidos na área bem como suas limitações práticas e conceituais. 0 relatório produzido baseava-se nos compromissos da "Declaração de Caracas" que se desdobrou em um documento intitulado "Princípios Orientadores para o Desenvolvimento da Atenção em Saúde Mental nas Américas", o qual serve hoje como base ética, técnica e política da reforma psiquiátrica. (Hirdes, 2009).

Assim, é em fins de 1980 que os movimentos sociais do Brasil associados à luta pelos direitos humanos culminaram na Reforma Psiquiátrica, garantindo uma nova Política de Saúde Mental, com as seguintes características: redução de leitos; controle sobre os hospitais psiquiátricos; rede de serviços alternativos para substituição dos leitos; aprovação da nova legislação de saúde mental - a Lei $n^{\circ}$ 10.216, de 6 de abril de 2001 -; incentivo ao processo de desinstitucionalização; e a saúde mental como parte integrante do sistema de educação do Sistema Único de Saúde (SUS). Segundo Mângia (2008), nesse processo identificam-se duas vertentes de enfrentamento: a tecnocrática, priorizando ações de influência na atuação dos profissionais que lidam com os doentes mentais, como desativação das celas fortes, proibição do eletrochoque e de novas internações; e a comunitária, preocupada com a participação dos doentes mentais e de seus familiares no processo de mudança.

A Portaria no 224, de 29 de janeiro de 1992 do Ministério da Saúde aparece como um documento em que se apresentam mudanças nas diretrizes referentes a diversas áreas de atendimento aos doentes mentais, contudo não são incluídas questões sobre os HCTP - Hospital de Custódia e Tratamento Psiquiátrico. Ela determina diretrizes do atendimento dos doentes mentais nos serviços de saúde mental, normatizando serviços como: atendimento ambulatorial com serviços de saúde mental (unidade básica, centro de saúde e ambulatório), Centros e Núcleos de atenção psicossocial (CAPS/NAPS), atendimento de urgência psiquiátrica em hospital-geral, leito psiquiátrico em hospital-geral, Hospital-Dia (HD). Enquanto que a Portaria n⿳o 106, de 11 de fevereiro de 2000 , passa a determinar os Serviços Residenciais Terapêuticos para os pacientes de longa permanência dos hospitais psiquiátricos (Piccinini e Oda, 2006).

Cabe destacar que a desinstitucionalização não se restringe a deslocar para a comunidade o centro da atenção, em contrapartida do hospício ou do manicômio, ainda que, como realidade concreta, esse seja o ponto principal desse processo de mudança da percepção da loucura e do tratamento do paciente (Hirdes, 2009).

Assim, a Lei no 10.216 , de 6 de abril de 2001 aparece como a maior conquista legislacional do movimento de Reforma Psiquiátrica e por esse motivo é considerada como uma data norteadora neste trabalho. Ela é promulgada como decorrência 
de um grande debate realizado entre profissionais de diversas áreas das ciências humanas e sociais, superando as fronteiras federativas do País. Ela "Dispõe sobre a proteção e os direitos das pessoas portadoras de transtornos mentais e redireciona o modelo assistencial em saúde mental”. Dessa forma, ela materializa discussões no que se referem a um maior controle quanto aos leitos psiquiátricos e internação em instituições asilares já existentes, trazendo o debate da desinstitucionalização para o seu interior, evidenciando uma preocupação social de uma nova forma do cuidado com os portadores de transtorno mental (Gonçalves e Sena, 2001).

\section{O Hospital de Custódia e Tratamento Psiquiátrico: a doença mental e o crime}

Com a Reforma Penal de 1984, o Manicômio Judiciário passa a ser chamado de Hospital de Custódia e Tratamento Psiquiátrico, alterações essas previstas no art. 99 da Lei de Execuções Penais e no Código Penal Brasileiro (arts. 96 e 97).

O Hospital de Custódia e Tratamento Psiquiátrico de Florianópolis (HCTP) é uma instituição pública, sob responsabilidade estatal. Este é um órgão de defesa social e de clínica psiquiátrica, constituindo-se em um misto de hospital-presídio. Tem como objetivo o tratamento psiquiátrico do paciente, preservando os direitos humanos e a sua dignidade, garantindo qualidade de vida e bom atendimento durante a hospitalização. Visa tratar e recuperar seus internos, buscando uma reintegração deles ao meio social e custodiar estes indivíduos que, por determinação judicial têm uma medida de segurança a cumprir pelo delito que cometeram (Cordioli e col., 2006).

As medidas de segurança aparecem no Código de 40 para preencher um espaço do direito penal deixado pelo código anterior, pois deixava os irresponsáveis e semirresponsáveis sem nenhuma sanção penal, e também sem nenhum encaminhamento real. Por esse motivo, esta foi uma das maiores novidades presentes no Código de 1940, ao contemplar reclamações, tanto dos legisladores quanto dos criminalistas, os que percebiam que os mecanismos de cura para o louco criminoso precisavam de mudanças. Assim, a repressão do delito estaria sendo substituída nesses casos pela medida de segurança como nova forma de prevenção individualizada do crime (Peres e Nery Filho, 2002; Corrêa, 1996).

Ainda que inicialmente pareça apenas uma mudança de nomenclatura, a "diferenciação que faz o código entre a pena e a medida de segurança é que na pena toda diversidade ou dúvida resulta a favor do indivíduo. Já, na medida de segurança, a diversidade ou dúvida resulta a favor da sociedade." (Corrêa, p. 149, 1996). Ou seja, legalmente as duas funcionam como sanção penal, porém enquanto a pena privilegia a sua função repressiva, a medida de segurança estará privilegiando a prevenção de um novo delito.

Há ainda outra diferença clara entre as duas: a pena é aplicada por um período de tempo prédeterminado, ou seja, ao condenar o indivíduo, já se apresenta o período desse confinamento; por outro lado, a medida de segurança tem duração indeterminada previamente, sendo encerrada somente com a cessação da periculosidade do doente mental. Isso obedece ao fato de a pena ser aplicada àqueles que são considerados imputáveis - a quem se pode atribuir culpa - e a medida de segurança é exclusivamente direcionada para os inimputáveis e para os semirresponsáveis. Com isso, a medida de segurança segue a ideia de Beccaria, de acordo com a qual, diante do criminoso, é "melhor evitar os delitos que castigá-lo", pois essa medida de segurança funciona impedindo que o louco criminoso, em função da sua periculosidade, reincida no crime (Peres e Nery Filho, 2002).

Caracterizada como eticamente neutra e fundamentada na sua utilidade, a medida de segurança serve ao fim de segregação tutelar ou de readaptação individual, sendo desprovida do caráter aflitivo da pena, pois é assistência, é tratamento, é medicina, é pedagogia. Se acarreta algum sacrifício ou restrição à liberdade individual, não é isso um mal querido como tal ou um fim colimado, mas um meio indispensável à sua execução (p. 346).

Ou seja, esse crime é tido como um fato sintomático da periculosidade do indivíduo louco criminoso, e como não é possível determinar antecipadamente quão perigoso esse indivíduo é, estabelece-se a medida de segurança por um período indeterminado, até que se constate cessada a periculosidade do 
indivíduo (Peres e Nery Filho, 2002).

Resumindo, de acordo com a legislação brasileira, a doença mental é causa excludente da culpabilidade, ou seja, os doentes mentais que cometeram algum crime são absolvidos. Ao serem absolvidos, não se lhes deve aplicar sanção e não deverão ser punidos, mas sim tratados. A medida de segurança servirá para que esse período de tratamento se efetive com internação nos manicômios judiciários, embasada na periculosidade do paciente, presumida por lei (Peres e Nery Filho, 2002).

A medida de segurança, que aparece no artigo 29, e sua determinação, funcionam como uma medida preventiva, enquanto que a periculosidade tem status de elemento jurídico, e como tal cabe ao juiz criminal determiná-la. Contudo, a antropologia criminal e as ideias de Lombroso permanecem influentes, e a periculosidade, nesse novo quadro, aparece como elemento central tanto para a definição da pena quanto para a ideia de prevenção criminal (Peres e Nery Filho, 2002; Carrara, 1987).

Ainda que a medida de segurança seja responsável por inserir a condição de atuação do direito penal diante da loucura através do tratamento e da prevenção, ela carrega consigo a maior aflição para o louco criminoso cumprindo a medida devido à indeterminação do seu término, visto que o paciente estará cumprindo a medida e permanecerá interditado na instituição até que o psiquiatra forense avalie como cessada a sua periculosidade, adquirindo caráter de prisão perpétua em diversos casos, pois há a especificação do tempo mínimo apenas (Peres e Nery Filho, 2002).

Perante essa situação, evidencia-se a necessidade da discussão sob a questão do doente mental no campo sociojurídico e a urgência em se rever a situação do "louco infrator". Sendo assim, buscando realizar um mapeamento inicial de incorporações dessa temática, o presente trabalho pretende identificar se houve alterações na produção científico-técnica do País no campo sociojurídico a partir do movimento de Reforma Psiquiátrica, em especial com a promulgação da Lei no 10.216, de 6 de abril de 2001. Dessa forma, foi feito um levantamento bibliográfico da produção científica do País, através dos meios virtuais de acesso com o objetivo de tentar visualizar o "estado da arte do debate" da produção acadêmica dessa temática na última década (2001-2011) nas áreas de produção de conhecimento das ciências humanas e sociais aplicadas (CAPES, 2009).

\section{Construindo o Instrumento}

Para alcançar o objetivo do presente trabalho, a construção de uma base de dados respondeu à necessidade de realizar um levantamento do universo de trabalhos encontrados em torno da temática da saúde mental no campo sociojudiciário, nos principais meios de publicação com acesso virtual.os critérios de inclusão/exclusão dos materiais examinados foram:

Nível, qual seja, nacional, no sentido de realizar uma busca sobre a produção científica do Brasil sobre a temática.

Periodização, no sentido de analisar a produção científica da última década referente à saúde mental no campo sociojudiciário nas áreas de conhecimento das ciências humanas e sociais aplicadas.

Natureza do material, no sentido de selecionar aqueles trabalhos de maior divulgação e prestígio científicos na área de conhecimento:

- Artigos e materiais divulgados no Portal de Periódicos Scielo.

- Dissertações e Teses disponibilizadas no Banco de Teses da CAPES - Coordenação de Aperfeiçoamento de Pessoal de Nível Superior.

A busca de material nesses meios deu-se através da definição de palavras-chave que compreendessem a temática. Para configurar uma busca exaustiva, de forma a incluir o maior número possível de trabalhos pertinentes, foi utilizada mais de uma palavra-chave. As palavras-chave utilizadas inicialmente foram saúde mental e transtorno mental, contudo, apesar da pertinência à temática, não se mostraram como bons critérios para esta pesquisa por não limitarem o universo, sendo excessivamente genéricas e incluindo uma infinidade de questões que perpassam a temática de saúde mental. Dessa forma, as palavras-chave de busca definidas foram saúde mental e crime; transtorno mental e crime; loucura e crime; doença mental e crime. A palavra crime foi incluída em todas as buscas com o intuito de limitar ao campo sociojudiciário. Juntamente com 
saúde mental, foram ainda utilizadas criminalidade, jurídico, sociojurídico, com as quais foram encontrados poucos trabalhos. Foram feitas ainda buscas com outras possíveis palavras-chave, contudo os resultados passaram a ser os mesmos do que com as palavras-chave definidas para este trabalho.

A definição da busca sobre a produção científica do Brasil a respeito da temática dá-se pelas características específicas do movimento de Reforma Psiquiátrica, compreendendo que sua trajetória e seus marcos colocam-no como um objeto único, sendo pertinente a busca na literatura em nível nacional.

Já a definição da periodicização dá-se pela aprovação da nova legislação de saúde mental - a Lei $n^{\circ}$ 10.216, de 6 de abril de 2001. Compreende-se aqui que este se constitui como um marco histórico no movimento da Reforma Psiquiátrica.

O material foi trabalhado a partir da inclusão de dados selecionados dos resumos na base de dados construída especificamente para este trabalho. Esta base de dados consta de onze (11) variáveis. Estas variáveis foram utilizadas para classificar e analisar os textos selecionados. O software empregado foi o Microsoft ACCESS versão 2007. Nesse suporte foram registrados os seguintes campos temáticos:

1. Código - numeração automática

2. Título - título do trabalho incluído na base de dados

3. Palavras-chave - as palavras-chave apontadas no trabalho

4. Autor(es) - nome do(s) autor(es)

5. Portal de Busca - onde foi publicado o trabalho, sendo Scielo ou CAPES

6. Palavra-chave de Busca - qual a palavra-chave utilizada para a busca no portal

7. Tipo de Produção - qual o tipo de trabalho: dissertação, tese, artigo

8. Ano - ano de publicação do trabalho

9. Titulação do Autor Principal - qual a titulação máxima do autor principal, quando disponível

10. Objeto de Análise - qual a problemática trabalhada no texto

11. Área de Conhecimento do Trabalho - qual a área de conhecimento a que pertence o trabalho

\section{Resultados e Análises}

O material bibliográfico registrado na base de dados foi observado visando avaliar, a partir dessas variáveis, a produção acadêmica encontrada e inserida na base sobre a temática da saúde mental no campo sociojurídico, buscando, assim, melhor apreender o "estado da arte do debate". Para tanto, tentou-se compreender (i) características da produção; (ii) perfil da produção científica; (iii) áreas e subáreas temáticas específicas. A partir dos resultados, foram pensadas algumas hipóteses que, a partir da literatura e de pesquisas recentes, pudessem indicar a situação do "estado da arte" desta discussão.

Sendo assim, algumas variáveis mostraram-se mais interessantes para a análise no presente trabalho. De todas as variáveis, a que foi considerada inválida é a Titulação do Autor Principal, isso porque na maior parte dos materiais encontrados no Portal de Periódicos Scielo não constavam informações sobre os autores, com exceção de seus e-mails para contato.

De uma busca apurada, com mais de uma palavrachave, foram encontrados 37 trabalhos no Scielo $(n=9)$ e na CAPES $(n=28)$ como sendo dedicados ao assunto. É possível constatar a escassez de trabalho quanto a essa temática ao compararmos com os resultados da busca por saúde mental e transtorno mental, os quais indicaram 1.038 e 230 trabalhos respectivamente no Scielo, e 2.834 e 672 no Banco de Dissertações e Teses da CAPES. A partir destes dados podemos pensar que a pouca produção da temática não está necessariamente relacionada com a problemática do campo da saúde mental em si, mas especificamente na sua relação com a questão da criminalidade e segurança pública. Considerando a aparente invisibilidade da questão, podemos supor que isso se deve ao seu caráter difuso e à falta de localização em uma área de saber específica e em uma política pública voltada a essa questão. Efetivamente, a problemática do "louco infrator" encontra-se sob encargo da área penal, ainda que as ações a serem encaminhadas nesse espaço sejam de responsabilidade da área de saúde (Mathes, 2010).

Outro ponto a ser destacado é que essa produção tem se localizado em nível de formação de mestrado, sendo que apenas dois dos 28 trabalhos encontra- 
dos na CAPES eram teses, assim como somente 9 trabalhos foram encontrados no Scielo. Isso pode indicar que esta não é uma temática privilegiada por profissionais que estão atuando na área e publicando trabalhos, como assistentes sociais, psicólogos, psiquiatras, enfermeiros, entre outros, mas vem sendo pensada no espaço acadêmico propriamente dito, no momento de uma pós-graduação.

Quanto às palavras-chave de busca, as que mais apresentaram resultados foram, em primeiro lugar, saúde mental e crime, com 13 trabalhos, e transtorno mental e crime, com 9 trabalhos. Somadas, estas representam a maior parte do material encontrado, sendo que as outras palavras-chave de busca indicaram resultados muito baixos - mas, considerando a escassez de material, não foram desconsideradas - de acordo com o seguinte gráfico.

\section{Gráfico I - Distribuição dos trabalhos por palavras- chave de busca (2001-2011)}

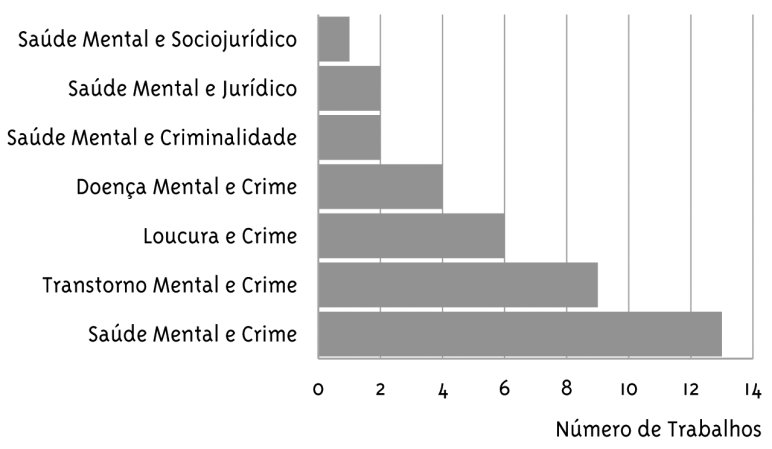

Fonte: Mathes, 2011

Quanto à periodicização, observou-se que houve maior produção dessa temática em 2006, seguida do ano de 2008, ainda que os trabalhos estejam distribuídos irregularmente durante os anos. É interessante destacar que a produção não se mostrou crescente durante a década, podendo indicar o não impacto das discussões sociais sobre o movimento da Reforma Psiquiátrica neste campo temático. 0 gráfico abaixo mostra a curva de produção acadêmica sobre a temática.
Gráfico 2 - Distribuição dos trabalhos por ano (200I2011)

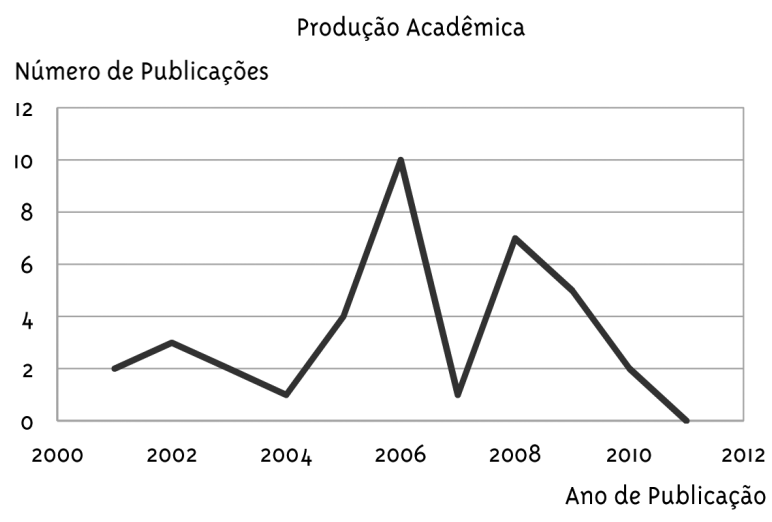

Fonte própria: Mathes, 2011

Já quanto às áreas de conhecimento que têm trabalhado a temática da saúde mental no campo sociojurídico, fica evidente a presença marcante dos saberes "psi" na produção de material. Enquanto que a Antropologia e a Sociologia contam com apenas um trabalho cada uma, a Psicologia $(n=7)$ e a Psiquiatria (5) têm 12 trabalhos. As outras áreas de conhecimento que aparecem discutindo essas questões são as Ciências Médicas ( $n=6)$; o Direito $(n=5)$; a Enfermagem (n=2); a História ( $n=2)$; a Saúde Coletiva $(n=2)$; a Saúde Pública ( $n=2)$; o Serviço Social $(n=2)$ e o espaço interdisciplinar de produção acadêmica, com dois trabalhos. A diversidade de saberes que participam da produção de conhecimento sobre a saúde mental no campo sociojurídico pode ser considerada mais um indicador da falta de clareza quanto a que área específica pertenceria esta discussão, assim como o fato de que a temática perpassa diversos campos profissionais e conteúdos teóricos. Contudo, apesar desse mosaico, ainda é possível perceber que é o saber "psi” o responsável pela maior parte da produção acadêmica deste tema. Este fato é justificado historicamente pela construção do espaço hospitalar e de toda a relação entre loucura e crime, desde Lombroso até os dias atuais (Mathes, 2010).

Quanto ao conteúdo dos trabalhos incluídos na base de dados, a questão central que orientou este artigo foi o de tentar perceber reflexos do movimento de Reforma Psiquiátrica nesse campo sociojurídico na produção científica do País. Dessa forma, o material encontrado confirma o que a literatura da 
área vem afirmando sobre a aparente negligência em discutir sobre esse espaço de intersecção da saúde mental e da área sociojurídica. Efetivamente, desde a lei no 10.216 de 2001 não se pode perceber uma forte presença de reflexos do movimento de Reforma Psiquiátrica. À guisa de ilustração, dentre as palavras-chave escolhidas pelos autores, a palavra que mais aparece é violência. Reforma Psiquiátrica, Cidadania e Direitos Humanos foram as únicas palavras que indicariam alguma consideração dessas discussões, aparecendo, contudo, uma vez cada uma, representando assim apenas três trabalhos do universo selecionado.

\section{Considerações Finais}

De um ponto de vista geral, a análise da informação coletada na pesquisa realizada em torno da produção bibliográfica da última década no Brasil permitiu constatar o caráter ainda tênue, tematicamente difuso e altamente complexo da produção na área de saúde mental no campo sociojurídico. A partir deste "estado da arte do debate" foi possível apreender as fragilidades dessa área de pesquisa, ainda que a situação do "louco infrator" seja uma questão historicamente relevante.

Se, no Brasil, os ecos das ideias dos movimentos de antipsiquiatria contribuíram com mudanças ao longo dos anos, isto não pode ser evidenciado na temática aqui estudada. Atualmente, com a lei de Paulo Delgado, prevê-se uma progressiva extinção dos manicômios, assim como a sua substituição por outras formas de atendimento, além de regulamentar a internação psiquiátrica. Vários Conselhos de familiares de doentes mentais e ONGs - nacionais e internacionais - têm apoiado o movimento antimanicomial.

Contudo, o "louco criminoso" não está inserido na mesma lógica. Efetivamente, o que se observa é uma situação anacrônica entre as mudanças preconizadas pelo movimento de Reforma Psiquiátrica e o Código Penal Brasileiro. Neste, quando a pessoa é considerada inimputável, a reclusão e o tratamento ambulatorial em hospital de custódia e tratamento psiquiátrico é uma consequência legal, independentemente do transtorno mental ou da necessidade individual. Essa situação decorre da periculosidade presumida, ficando internado por um prazo mínimo de 1 (um) a 3 (três) anos. A utilização do CAPS - Centro de Atenção Psicossocial - como rede de tratamento só faz parte desse processo após o período inicial e/ou de forma concomitante à internação no HCTP. (Barros, 2010; Mathes, 2010; Ministério da Saúde, 2005).

Quanto à legislação sobre saúde mental, se o Decreto de 1934 mostrou e evidenciou a medicina preocupada com a profilaxia e a higiene mental, visando superar os males que afetavam o povo, foi com o projeto de lei de 1989 que a percepção sobre a reforma psiquiátrica mostrou-se imprescindível, especificamente no que tange à luta pelos direitos humanos e sociais dos doentes mentais. Após este decreto, há a promulgação da Lei 10.216 (2001), a qual é na realidade um documento de intenções. Nela estão presentes princípios como a proteção dos doentes mentais e o anseio de melhorias no atendimento desse segmento da população. De fato, esta lei atual anseia garantir os direitos básicos do doente mental, reconhecendo a internação psiquiátrica integral não como um problema, mas como mais um recurso terapêutico - desde que o atendimento seja de boa qualidade -, ainda que destaque a urgência de políticas que objetivem a desospitalização (Piccinini e Oda, 2006). Porém, a proteção da garantia dos direitos dos portadores de transtorno mental que cometeram delitos, assim como o seu atendimento, não parece ser uma preocupação deste movimento.

Quando se fala de Manicômio Judiciário, a ambiguidade está sempre presente, ao se pensar nas dicotomias "guarda/enfermeiro, presos/pacientes, pena/tratamento, hospital/prisão" envolvidas nesse contexto (Delgado, p. 57, 1992). Esse espaço, que comporta pacientes internados por longos períodos ou aguardando os exames periciais, cumpre duas classes de funções, a de custodiar, mas também a de tratar doentes mentais perigosos, definindo-se como um misto de hospital e presídio. Esta característica seria responsável pelo caráter ambíguo da instituição e dos profissionais inseridos nela, tanto pelo fato de custodiar e tratar ao mesmo tempo, como pelo fato de as ações terapêuticas e diagnósticas do médico responderem aos imperativos e normas do sistema jurídico penal. Segundo Carrara (1987 apud Rebelo, 2004, p. 69), as práticas e os pensamentos 
jurídicos e médicos encontram no manicômio judiciário o espaço privilegiado para sua junção.

Porém, apesar da mudança de nomenclatura, os hospitais de custódia constituem-se em uma instituição com o duplo sentido de "custodiar e tratar doentes mentais perigosos" (Cordioli, p. 22, 2004). Esta característica seria responsável pelo caráter ambíguo da instituição e dos profissionais inseridos nela, tanto pelo fato de custodiar e tratar ao mesmo tempo, como pelo fato de que as ações terapêuticas e diagnósticos do médico são medidos pelo sistema jurídico penal, sendo ainda uma influência nas limitações técnicas do hospital.

Apesar dos avanços alcançados na legislação e na assistência aos portadores de transtorno mental, a temática da medida de segurança tem sido pouco abordada e aprofundada na Reforma Psiquiátrica Brasileira.

Nesse sentido, é preciso destacar, mais uma vez, que a luta antimanicomial, o questionamento das condições de vida e a defesa dos direitos da população internada por decisão judicial não têm sido, até o momento, incluídos na agenda da reforma psiquiátrica em curso no Brasil. A participação das profissões do campo social - Serviço Social, Psicologia, Direito - no registro desta "omissão" poderia representar um começo de ruptura com esse silenciamento que caracteriza práticas discursivas e não discursivas de diversos tipos de agentes neste campo.

Por último, faz-se necessário explicitar que este é um levantamento exploratório sobre a produção científica em torno desta área temática, e que a construção deste "estado da arte do debate" permanece, por enquanto, no terreno de um primeiro mapeamento empírico junto ao qual as considerações de natureza analítica aqui vertidas, embora apresentem sustentação conceitual e empírica, não possuem valor conclusivo, permanecendo ainda em um nível de hipóteses suscetíveis de orientar as próximas etapas de pesquisa em torno do tema.

\section{Referências}

ABDALLA-FILHO, E.; ENGELHARDT, W. A prática da psiquiatria forense na Inglaterra e no Brasil. Revista Brasileira de Psquiatria, São Paulo, v. 25, n. 4, p. 245-8, 2003.
ADORNO, S. Sistema penitenciário no Brasil: problemas e desafios. Revista USP, São Paulo, n. 9, p. 65-78, 1991.

ALVES, D. S. N (Coord.). Conversando com o Ministério Público: o Ministério Público e a reforma psiquiátrica. Rio de Janeiro: Instituto Franco Basaglia, 2004. Disponível em: <http:// www.inverso.org.br/blob/127.pdf >. Acesso em: 10 dez. 2009.

AMARANTE, P. D. de C. Psiquiatria social e reforma psiquiátrica. Rio de Janeiro, Fiocruz, 1994 .

BARROS, C. S. M. Aplicação da reforma psiquiátrica e da política de saúde mental ao louco infrator. Revista Jurídica Consulex, Brasília, ano XIV, n. 320, 15 maio, 2010.

\section{COORDENAÇÃO DE APERFEIÇOAMENTO} DE PESSOAL DE NÍVEL SUPERIOR. Tabela de Áreas de Conhecimento. Brasília: CAPES, 2009. Disponível em: <http://www.capes.gov.br/ avaliacao/tabela-de-areas-de-conhecimento>. Acesso em: 15 jul. 2011.

CARRARA, S. L. Crime e loucura: o aparecimento do manicômio judiciário na passagem do século. 1987. Dissertação (Mestrado em Antropologia Social) - Museu Nacional da Universidade Federal do Rio de Janeiro, Rio de Janeiro.

COHEN, C. A periculosidade social e a saúde mental. Revista Brasileira de Psiquiatria, São Paulo, v. 21, n. 4, dec. 1999. Disponível em: <http://www.scielo.br/ scielo.php?script=sci_arttext\&pid=S1516$44461999000400006 \& \operatorname{lng}=\mathrm{en} \& \mathrm{nrm}=\mathrm{iso}>$. Acesso em: 18 fev. 2010.

CORDIOLI, M. S.; BORENSTEIN, M. S.; RIBEIRO, A. A. A. Hospital de custódia: os direitos preconizados pela reforma psiquiátrica e a realidade dos internos. Escola Anna Nery, Rio de Janeiro, v. 10, n. 4, dez. 2006 . Disponível em: <http://www.scielo. br/scielo.php?script=sci_arttext\&pid=S1414 $81452006000400008 \& \operatorname{lng}=e n \& n r m=i s o>$. Acesso em: 13 jul. 2011. 
CORDIOLI, M. S. Hospital de custódia e tratamento psiquiátrico: os direitos preconizados pela reforma psiquiátrica e a realidade dos internos. 2004. Trabalho de Especialização em Atenção Psicossocial. - Centro de Ciências da Educação, Universidade do Estado de Santa Catarina, Florianópolis.

CORRÊA, J. M. Um estudo jurídico e político sobre saúde mental. 1996. p. 126. Tese (Doutorado em Direito) - Universidade Federal de Santa Catarina, Florianópolis.

DARMON, P. Médicos e assassinos na Belle Époque: a medicalização do crime. Rio de Janeiro: Paz e Terra, 1991.

DELGADO, P. G. As razões da tutela. psiquiatria, justiça e cidadania do louco no Brasil. Rio de Janeiro: Editora Te Corá, 1992.

FOUCAULT, M. Historia de la sexualidad. México: Siglo XXI, 1978. v. 1.

FREIDSON, E. Professional powers. A study of the institutionalization of formal knowledge. Chicago: The University of Chicago Press, 1988.

GASTAL, F. et. al. Reforma psiquiátrica no Rio Grande do Sul: uma análise histórica, econômica e do impacto da legislação de 1992. Revista de Psiquiatria do Rio Grande do Sul, Porto Alegre, v. 29, n. 1, abr. 2007. Disponível em: <http://www. scielo.br/scielo.php?script=sci_arttext\&pid=So101$81082007000100020 \& \operatorname{lng}=\mathrm{pt} \& \mathrm{nrm}=\mathrm{iso}>$. Acesso em: 12 jul. 2011.

GONÇALVES, A. M.; SENA, R. R. A reforma psiquiátrica no Brasil: contextualização e reflexos sobre o cuidado com o doente mental na família. Revista Latino-Americana de Enfermagem, Ribeirão Preto, v. 9, n. 2, abr. 2001. Disponível em: <http://www.scielo.br/ scielo.php?script=sci_arttext\&pid=So104$11692001000200007 \& \operatorname{lng}=p t \& n r m=i s o>$. Acesso em: 15 jul. 2011.

HARRIS, R. Assassinato e loucura. Medicina, leis e sociedade no fin de siècle. Rio de Janeiro: Rocco, 1993.
HIRDES, A. A reforma psiquiátrica no Brasil: uma (re) visão. Ciência \& Saúde Coletiva, Rio de Janeiro, v. 14, n. 1, fev. 2009. Disponível em: <http://www.scielosp. org/scielo.php?script=sci_arttext\&pid=S1413$81232009000100036 \& \operatorname{lng}=e n \& n r m=i s o>$. Acesso em: 08 fev. 2010.

JABERT, A. Formas de administração da loucura na Primeira República: o caso do estado do Espírito Santo. História, Ciências, Saúde Manguinhos, Rio de Janeiro, v. 12, n. 3, p. 693-716, set./dez. 2005.

MACHADO, R. et al. Danação da norma: a medicina social e construção da psiquiatria no Brasil. Rio de Janeiro: Graal, 1978.

MANGIA, E. F. Psiquiatria institucional: do hospício à reforma psiquiátrica. Cadernos de Saúde Pública, Rio de Janeiro, v. 24, n. 3, mar. 2008. Disponível em: <http://www.scielosp. org/scielo.php?script=sci_arttext\&pid=So102$311 \mathrm{X} 2008000300028 \& \mathrm{lng}=\mathrm{pt \& nrm}=$ iso $>$. Acesso em: 08 fev. 2010.

MATHES, P. G. Criminalização da loucura e medicalização do crime: trajetórias e tendências da psiquiatria forense. 2010. 140 f. Dissertação (Mestrado em Serviço Social) - Centro SócioEconômico - Universidade Federal de Santa Catarina, Florianópolis.

MATHES, P. G. Perícia técnica e arbitragem social: o caso do serviço social na área criminal do poder judiciário de Santa Catarina. Relatório final PIBIC CNPq/UFSC. Florianópolis, agosto de 2007.

MINISTÉRIO DA SAÚDE. Reforma psiquiátrica e política de saúde mental no Brasil. Brasília, DF, 2005. Disponível em: <http://bvsms.saude.gov.br/ bvs/publicacoes/Relatorio15_anos_Caracas.pdf >. Acesso em: 10 jul. 2011.

MITJAVILA, M. R. Responsabilidade e periculosidade criminal: olhares da medicina psiquiátrica na contemporaneidade. In: CONGRESSO BRASILEIRO DE SOCIOLOGIA, 14., Rio de Janeiro, 2009. Anais... Rio de Janeiro: Sociedade Brasileira de Sociologia, 2009. 
MITJAVILA, M. R. Perícia técnica e arbitragem social: um estudo sobre o serviço social do poder judiciário no Estado de Santa Catarina. In: ENCONTRO NACIONAL DE PESQUISADORES EM SERVIÇO SOCIAL, 9., Porto Alegre, 2004. Anais... Brasília: Associação Brasileira de Ensino e Pesquisa em Serviço Social. Associação Brasileira de Ensino e Pesquisa em Serviço Social, 2004. 1 CD-ROM.

MITJAVILA, M.R. Perícia técnica e arbitragem social: o caso do serviço social na área criminal do poder judiciário de Santa Catarina. Relatório técnico de pesquisa CNPq. Brasília, DF, 2006.123 p.

MITJAVILA, M; ORTEGA, E. El preventivismo sanitarista y la institucionalización del Trabajo Social en el Uruguay neobatllista: una indagación genealógica. Revista Katálysis, Florianópolis, v. 8, n. 2, jul./dez., p. 211-24, 2005.

PAVEZI, I. B. A criação do indivíduo inimputável pela psiquiatria forense como uma forma de exclusão e controle social na contemporaneidade. In: Surveillance in Latin America - vigilância, segurança e controle social. Curitiba: PUCPR, 2009. p. 300-311.
PERES, M. F. T.; NERY FILHO, A. A doença mental no direito penal brasileiro: inimputabilidade, irresponsabilidade, periculosidade e medida de segurança. História, Ciência, Saúde-

Manguinhos, Rio de Janeiro, v. 9, n. 2, 2002.

PICCININI, W.; ODA, A. M. G. R. História da psiquiatria: a loucura e os legisladores. Psychiatry Online Brasil, São Paulo, v. 11, n. 3, mar. 2006. Disponível em: <http://www.polbr.med.br/anoo6/ walo3o6.php>. Acesso em: 10 jul. 2011.

REBELO, F. R. A penitenciária de Florianópolis e a medicalização do crime (1935-1945). 2004. 151f. Dissertação (Mestrado em Saúde Pública) - Universidade Federal de Santa Catarina, Florianópolis.

VENÂNCIO, A. T. A. Ciência psiquiátrica e política assistencial: a criação do Instituto de Psiquiatria da Universidade do Brasil. História, Ciências, Saúde-Manguinhos, Rio de Janeiro, v. 10, n. 3, p. 883-90o, set./dez., 2003. 